\title{
The meaning of caring for nursing students in a baccalaureate nursing program: An arts-based inquiry
}

\author{
Karen Parsons, Caroline Porr, April Pike, Paula Kelly \\ Faculty of Nursing, Memorial University, St. John's, Newfoundland and Labrador, Canada
}

Received: April 16, 2019

Accepted: July 25, 2019

Online Published: August 13, 2019

DOI: $10.5430 /$ jnep.v9n11p35

URL: https://doi.org/10.5430/jnep.v9n11p35

\begin{abstract}
Objective: To determine the meaning of caring for nursing students in order to inform development of a caring curriculum for a four-year Bachelor of Nursing Program.

Methods: A hermeneutic phenomenological method was employed to explore the meaning students ascribed to caring in nursing. Students drew from their own experiences within the context of nursing education. Arts-based inquiry was used as the medium to elicit students' reflections of the meaning of caring. Seven nursing students participated in the study. Each student was asked to paint a picture capturing the meaning of caring in nursing, followed by one semi-structured audio-recorded interview. Data analysis followed the seven-step method of contextual analysis described by Diekelmann, Allan and Tanner (1989), and incorportated the methods of van Manen (1990).

Results: Four themes emerged from the interview data: a) caring comes from within, b) caring is being the best you can be, c) caring is providing holistic care, and d) caring cannot be taught.

Conclusions: Arts-based inquiry and the phenomenological method enabled in-depth exploration of the meaning of caring in nursing for seven nursing students. Arts-based inquiry can serve as an effective educational strategy for facilitating and fostering nurse caring among nursing students. The findings from this study have important implications for designing and implementing a caring curriculum in a baccalaureate nursing program including ensuring a caring learning environment is established for nursing students. A caring curriculum will advance student caring, and, ultimately, promote higher quality nursing care delivery.
\end{abstract}

Key Words: Caring, Arts-based inquiry, Nursing students, Curriculum, Phenomenology

\section{INTRODUCTION}

Providing safe, compassionate, competent and ethical care is a longstanding nursing value and ethical responsibility to which all nurses are bound ${ }^{[1]}$ and a critical practice standard taught in all schools of nursing across Canada. ${ }^{[2]}$ Caring is the essence of nursing and the foundation of competent nursing care delivery. ${ }^{[3]}$ The practice literature is replete with references to caring; caring has been described as a way of being and manifest through nurse compassion, competence, confidence, conscience and commitment. ${ }^{[4]}$ Literature references to caring attributes, caring models, caring theories, caring environments and caring science provide evidence of the signficance of caring. ${ }^{[5-8]}$ Caring science is the core structure of Watson's Theory of Human Caring (1997) that is prominently featured in the practice literature. ${ }^{[9]}$ It is well documented that effective caring interventions mitigate risk to patient safety and enhance patient outcomes, and compassionate care promotes patient satisfaction. ${ }^{[10]}$ How-

\footnotetext{
* Correspondence: Karen Parsons; Email: karenp@mun.ca; Address: Faculty of Nursing, Memorial University, St. John’s, Newfoundland and Labrador, Canada.
} 
ever, authentic nurse caring is challenged in today's turbuluent health care environments by several factors including increasing workloads, patient complexity and advances in technology. ${ }^{[11]}$ In fact, improving the levels of compassionate care delivery in hospital institutions has garnered much attention by consumers of healthcare, healthcare administrators $^{[12]}$ and policymakers. ${ }^{[13]}$ The Department of Health in the UK, for example, has adopted compassion as one of the national health values in response to patient criticism of nursing care and has developed national metrics with quality indicators focused on patients' experiences of being shown caring respect and dignity.

Nurse educators are responsible for preparing nursing students with the requisite knowledge, skills and attitudes to implement efficacious caring interventions. This can be challenging given the multitude of factors within (e.g., workload) and outside the health care environment (e.g., social media and generational differences) that may cause shifts in students' attitudes towards nursing's care ethic as they progress through the nursing program. ${ }^{[14]}$ Despite this, there are few studies examining perspectives of caring among nursing students ${ }^{[15,16]}$ who are Gen Xers or Millenials, from which nurse educators can draw guidance or extract baseline information about how or to what extent nursing students value caring. Moreover, there continues to be multiple definitions of caring with no two nursing theorists or nurse clinicians sharing identical perspectives. Increasingly, in the nursing education literature, caring and empathy are given equal weight or treated as synonymous terms ${ }^{[17-19]}$ leading one to wonder if nursing students are losing seminal theoretical grounding in nurse caring.

In order for nurse educators to carry out their responsibilities and optimize student care behaviors, nurse educators must be armed with fundamental understanding of what students conceive is caring and the significance of caring students assign to nursing practice. Hence, we conducted a phenomenological study of the meaning of caring among baccalaureate nursing students to provide our faculty of nurse educators with this fundamental understanding. Arts-based inquiry was used as an approach to help students reflect on the meaning of caring. We anticipate that our findings will become the starting point from which nurse educators can then identify and implement effective educational experiences and teaching strategies to foster and to advance student caring throughout the curriculum.

\section{Purpose and objectives}

The purpose of this study was to explore the meaning of caring for nursing students in a Bachelor of Nursing (BN) program in order to inform the development of a caring cur- riculum across four years of the BN curriculum.

The specific objectives of the study were:

(1) To identify the meaning of caring from the nursing student perspective.

(2) To identify how nursing students have experienced the nurse-patient caring relationship in clinical practice.

(3) To identify sources of support for, and deterrents to, the development of the nurse-patient caring relationship.

\section{METHODS}

\subsection{Study design}

A hermeneutic phenomenological method was used to determine the meaning of caring for first and fourth year nursing students in a BN program. Hermeneutic phenomenology was chosen as it is suited for understanding the meaning of experiences, within context, as they are lived. ${ }^{[20]}$ The meaning nursing students ascribed to caring in nursing was based on their own experiences within the context of nursing education. Arts-based inquiry was used as a medium for students to reflect on the meaning of caring. In the world of interpretation, many philosophers have argued that understanding is achieved through the process of creation. ${ }^{[21,22]}$ The act of painting a picture provided a structure for ongoing dialogue as to the lived experience of caring. It acted as a venue to connect students' ideas about caring to real patient encounters and the lived world.

\subsection{Sampling procedures and recruitment}

This study took place at Memorial University, Faculty of Nursing, Newfoundland, Canada. During the first week of classes in 2016 and 2017, a Research Assistant (RA) invited a convenience sample of first year nursing students and fourth year nursing students to participate in the study. During this time the RA described the study and provided an opportunity for the students to ask questions. An information sheet was provided to the potential participants that further explained the study. Students who wished to take part in the research were asked to contact the RA. Additionally, recruitment posters were placed on posterboards throughout the Faculty of Nursing. The RA met with individual students who agreed to participate in the study to answer additional questions, obtain written consent, provide painting materials, and arrange for a time and place for the interview. Only first and fourth year nursing students were chosen for recruitment as neither class had any teacher-learner relationship with the Primary Investigator (KP). Furthermore, it was felt that there may be differences in first and fourth nursing students' perceptions of caring and caring behaviours in their nurs- 
ing practice as a result of their experiences throughout the nursing program.

Approval to conduct the study was obtained from the Health Research Ethics Authority, Memorial University. The researchers were aware that students should be treated as a vulnerable population. Students' abilities to exercise free choice may have been potentially influenced by the power dynamics between them and the faculty members, potentially compromising autonomy. Therefore, to ensure students that confidentiality and anonymity would be maintained at all times, a RA was used for recruitment, and class professors were unaware of who participated in the research. This was intended to ensure that students invited to participate did not feel any pressure to participate if they believed that failure to volunteer may lead to disapproval, loss of favor, or even a decreased grade. This perception may have made refusing participation difficult.

\subsection{Participant characteristics}

Three nursing students who had recently completed year one of the $\mathrm{BN}$ program and four nursing students currently in year four of the $\mathrm{BN}$ program (six females, one male) participated in this study. The students ranged in age from 18-26 years of age. The BN program offers nursing students both theory and practical experience. Throughout the four years students rotate through a variety of clinical placements including care of the older adult, medicine, surgery, pediatrics, maternal-child, mental health and community health. In year one of the BN program students complete only one clinical placement, care of the older adult in longterm care.

\subsection{Data collection}

Students were asked to paint a picture that they felt represented the meaning of caring in nursing. They were instructed that the painting could be completed at a time and place of their convenience. Painting supplies were provided and all students chose to complete the painting at home. The time range for completion of the painting was one to four weeks. Following completion of their painting each student was asked to contact the RA to set up a convenient time and place for the interview. Each student participated in one semistructured audio-recorded interview with the first author (KP) (see Table 1 for semi-structured interview guides). Students were asked to bring their painting to the interview so that they could refer to it as they answered questions about how their understanding of caring was reflected in the painting.

Table 1. Semi-structured interview guide

1. Tell me what it means to you to be a caring nurse.

2. Can you tell me about how your understanding of caring is reflected in your painting?

a. Tell me how the colors in the painting helped you articulate what it means to be a caring nurse. (Prompt if required)

b. Are there any other elements of the painting that you feel highlight the meaning of caring in the nurse-patient relationship? (Prompt if required)

3. What were some of the challenges you encountered while painting a picture of caring in nursing?

4. How did the painting activity help you understand the meaning of caring?

5. Tell me a story about a time in your clinical practice that you observed a nurse exhibiting caring behaviors toward a patient. Do you have other examples?

6. Give me an example of a time when you felt you were exhibiting caring behaviors toward a patient you encountered in your clinical practice. Do you have other examples?

7. How do you feel you have been encouraged and supported within your nursing studies to develop caring nurse-patient relationships in the clinical areas you have worked. Can you provide me with examples?

8. How could the nursing curriculum better prepare nursing students to learn about and develop caring nurse-patient relationships?

\subsection{Data analysis}

Each taped nterview was transcribed verbatim and then reviewed with the typed text to ensure accuracy of data transcription. Data analysis followed the seven-step method of contextual analysis described by Diekelmann, Allan and Tanner (1989), ${ }^{[23]}$ as shown in Table 2 and incorportated the methods of van Manen (1990). ${ }^{[20]}$ Although the analysis appears linear "the thinking that accompanies hermeneutical scholarship is reflective, reflexive, and circular in nature". [24] Phenomenological interpretation is a continuous process of relating the part of the text to the whole of the text, and any or all passages are always understood in terms of their relationship to the larger whole. ${ }^{[25]}$ The specific approach used to uncover the thematic aspect of the meaning of caring was the 
selective or highlighting approach outlined by van Manen ${ }^{[20]}$ whereby the text is read, line by line, several times and statements that appear to be revealing of the phenomenon are highlighted. Although KP took the lead in the identification of themes, to ensure credibility of the findings each interview was analyzed by at least two members of the research team. During analysis the researcher maintained a log to ensure the researcher's "decision trail"[20] could be followed.

Table 2. Seven-step method of textual analysis

1. Each text was read in its entirety and reflected upon to discover the thematic aspects of the narrative and to obtain an overall understanding of what was discussed by the participants.

2. The themes were identified by highlighting statements that appeared to be revealing about the questions being asked.

3. An interpretive summary of each interview was written.

4. Each interview was read against all other interviews and relational themes were identified.

5. Patterns were extracted to see how the pieces fit and to sense was made of the data.

6. Other relevant texts were used to enhance the interpretation.

7. Credibility of the interpretive analysis was ensured.

We did not use a set threshold to determine data saturation but were guided by the results of our analyses. As it is near impossible to reach total saturation, as there is always the potential to discover new things in data, ${ }^{[26]}$ we reached a point where we determined that new discoveries would not add further insights, and we had reached a sufficiently robust understanding of the phenomenon.

To ensure that the data were trustworthy, Lincoln and Guba's evaluative criteria ${ }^{[27]}$ were used, including credibility, conformability, and dependability, and transferability. To ascertain the credibility of the data, the researcher collected data through prolonged engagement with the participants and immersion in their ideas, and constantly summarized and repeated their statements during the interviews for clarification of their meaning. The themes were shown to two of the participants for comments. For the conformability of the data, the complementary views of two faculty members with an expertise in qualitative research were also taken. Finally, the interpretation of the data was compared to what was already known about the phenomena from the literature to determine if it was transferable.

\section{RESUltS}

Four themes, each with subthemes, emerged from the interview data: a) caring comes from within, b) caring is being the best you can be, c) caring is providing holistic care, and e) caring cannot be taught (see Table 3). Together the themes 'paint a picture' of the meaning of caring for seven nursing students. The nursing students' stories of the perception of the caring self, the perception of those whom they care for, and the integration of caring behaviors in their individual nursing practice reveal that caring is still viewed as a core concept in the nursing profession for these students; albeit one that cannot be taught.

Table 3. Themes and subthemes

\begin{tabular}{|c|c|c|}
\hline Themes & & Subthemes \\
\hline 1. & Caring comes from within & $\begin{array}{l}\text { 1. Caring is being present } \\
\text { 2. Caring is putting oneself in the patient's place } \\
\text { 3. Caring is warmth } \\
\text { 4. Caring is developing therapeutic relationships }\end{array}$ \\
\hline 2. & Caring is being the best you can be & $\begin{array}{l}\text { 5. Caring is being competent } \\
\text { 6. Caring is being brave } \\
\text { 7. Caring is expecting nothing in return }\end{array}$ \\
\hline 3. & Caring is providing holistic care & $\begin{array}{l}\text { 8. Seeing the patient as having social and emotional needs } \\
\text { 9. Seeing the patient as person }\end{array}$ \\
\hline 4. & Caring cannot be taught & $\begin{array}{l}\text { 10. Caring can be embraced } \\
\text { 11. Caring can be facilitated }\end{array}$ \\
\hline
\end{tabular}




\subsection{Caring comes from within}

Students talked about caring as something more than a physical act of doing; it was something that was internal and individualized to the nurse; it was a part of who they were and what connected them emotionally and spiritually to the patient. The theme caring comes from within presented itself in four ways: caring is being present, caring is putting one's self in the patient's place, caring is warmth, and caring is developing therapeutic relationships.

That inner feeling that you know you want to help people; that it really just comes from within. (4th year nursing student)

\subsubsection{Caring is being present}

Being present was a significant theme throughout all of the interviews for both first and fourth year nursing students. Being present was more than just being physically in the same room with the patient, it was a connection or a knowing that often exceeded verbalization. Being present was about truly listening, comforting and being in the moment.

I think that being able to comfort a patient or family or knowing what supports are there for them, that is caring to me; to be able to know what they need in that moment and being able to provide that space for them to grieve. (4th year nursing student)

Another student recounted an authentic moment he had with his patient.

I just think even being there and listening - like I didn't have to say a word but just being there and listening, that patient told me after, 'thank-you so much'. And I could tell that he was really appreciative of me just listening. Yeah, just being there and listening because I don't think the other nurses did that. (4th year nursing student)

\subsubsection{Caring is putting oneself in the patient's place}

Three students discussed caring as mentally putting themselves in the patient's place and being able to imagine 'walking in the patient's shoes'.

To illustrate:

My patient had dementia and was unresponsive and she looked really unkept in the bed, and I thought 'I'm going to get an orange stick and clean out her nails and wash them for her'. The nurse I was with said 'don't worry about it' but I said 'I have time, that's fine.' So I ran off and got the orange stick and everything and I came back and washed out her nails and stuff. For me that kind of stuck in my mind because my patient didn't know what was going on and I was thinking that maybe they could; they knew and I was thinking, if it was me in the bed or like my grandmother, I wouldn't want somebody to neglect that part of her just because they didn't think they had enough time or the patient wouldn't know. So I carried that over to the rest of my clinical and kind of think about it that way if somebody asks for a fresh slice of toast or something, I always say, like 'OK' because if that was me that would be what I would want. (4th year nursing student)

\subsubsection{Caring is warmth}

When talking about caring students often discussed it in terms of being warm as opposed to being cold. Exuding warmth towards the patient and feeling warmth in return was a common theme. One participant painted the sun to articulate this warmth as the essence of caring.

I guess even stereotypically when you think of caring you think of the warmth. You think of just how it makes you feel and I was just thinking of like a warm embrace. (1 th year nursing student) (see Figure 1).

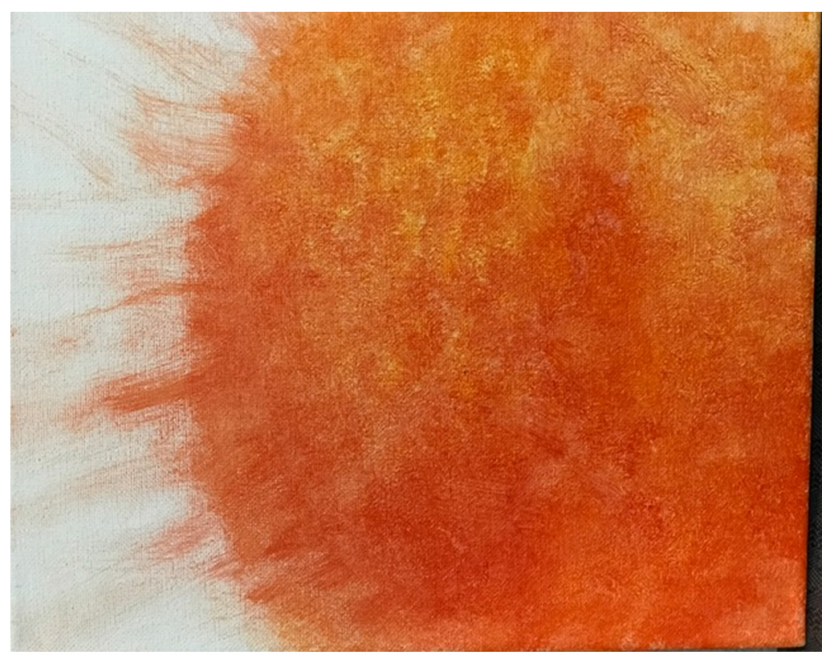

Figure 1. Painting by fourth year student Description: Caring comes from within: Caring is warmth

Another student stated:

You can go in and do medical things but that doesn't mean you are showing your patient that you care. I actually feel like that's one of the most important things in nursing. Yes, it's important to get the medical aspect right but if you go and you're cold and you're not nice and you don't care, then why are you doing any of it. (1st year nursing student)

\subsubsection{Caring is developing therapeutic relationships}

Caring also meant taking the time to get to know the patient, to sit and listen or talk. These acts of caring were not defined by time but by quality of the interaction. The use of touch was also viewed as central to developing the therapeutic relationship with the patient and the patient's family. 
What I find especially in long term care clinicals is most of the time yes, you have to do morning care and do like all the physical stuff but most of the time they just really need someone to talk to and so taking that half hour to an hour out of your day and just talking to someone and yes, it doesn't seem like something you would like classify as a job requirement but it's the caring part of nursing. (1st year nursing student)

I feel like with patients there is a sense of vulnerability, so I feel like touching kind of connects you with that person and you can kind of be with them on that level, like there's kind of a sense of a relationship. (1st year nursing student)

Yeah, it's just kind of taking the time, being a nurse especially in acute care is very busy but it makes a big difference just to spend those extra couple of minutes really getting to know your patient and it makes a big difference in their care too. (4th year nursing student)

\subsection{Caring is being the best you can be}

When discussing the meaning of caring, students talked about how important it was that they did their best. Being their best included being knowledgeable and competent when providing care. The ability to provide competent care included being skillful but doing so in a manner that was impartial and brave yet expecting nothing in return. The theme caring is being the best you can be has three subthemes; caring is being competent, caring is being brave, and caring is expecting nothing in return.

\subsubsection{Caring is being competent}

For the students in this study, providing competent care meant providing evidence-based care to the best of their ability and within hospital policy. It also meant providing care that is culturally competent.

Just be the best human you can be to that individual in that given time. (1st year nursing student)

Nursing is being up-to-date on your practice and caring is going out and having the research and the knowledge of what's best for your patient and keeping up-to-date on that to provide the best care possible for your patients. (4th year nursing student)

I have the map there [painting] and that represented to me cultural competence in nursing. So again, getting to know your patient and if they have a culture that you're not familiar with, then research it. There are a lot of different cultures obviously that come to the hospital and you know, some people have language barriers and being able to get a translator and somebody to be able to provide the best care to your patient. (4th year nursing student) (see Figure 2)

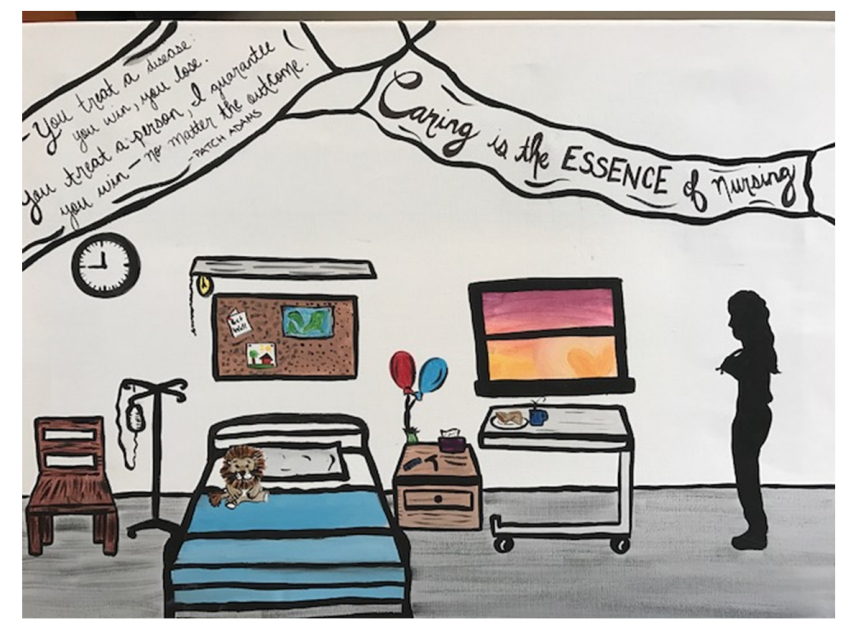

Figure 2. Painting by fourth year student

Description: Caring is being the best you can be: Caring is being competent

To be a caring nurse I feel like you have to be competent in your practice, understand policy and follow that policy and give the best care that you can for that individual. (1st year nursing student)

\subsubsection{Caring is being brave}

Advocating for evidence-based informed-practice in front of other nurses and physicians was seen as very important to two fourth year students. They found this to be quite challenging and requiring bravery.

So the lion in the painting represents bravery, so caring in nursing is also being brave especially as a student or a new nurse. Sometimes it's really hard to step up and say that you know what's best for your patient. For example, like standing up to a physician and saying, 'I really think that they need this' or even just calling a doctor on the phone sometimes can be a little bit intimidating if you think that there's something not right with your patient. Being able to stand up and advocate for your patient and you know with other nurses too, being a new nurse coming in and saying 'what we have been taught might be different from what you have been doing but this is evidence-based, this is what is going to provide the best care for my patient, so I'm going to do it this way'. So that's the bravery in nursing. (4th year nursing student) (see Figure 2)

We have a couple of new practices based on research and evidence-based practice and sometimes its difficult to put that forward to nurses who have been doing it a different way for a long time. (4th year nursing student)

\subsubsection{Caring is expecting nothing in return}

One student explained that for her caring meant being altruistic; likening altruism to the sun that she drew in her painting. 
Like the sun, nurses do what they do innately, because of what they are and who they are, not to reap rewards. Evident in this student's narrative was an appreciation of altruism as an underlying principle and attitude of the nurse role that is manifest through nurse caring.

The nurse will help you with your daily activities. Nurses will provide your medications, assess your overall wellbeing and like the sun, a nurse has many roles, but they do these things because it's their role, not because they're looking for something in return. (4th year nursing student)

\subsection{Caring is providing holistic care}

Students revealed that they believed caring should be more than just attending to patients' physical needs. Students viewed caring as holistic - caring is considering the patient's needs as an emotional level beyond the physical signs and symptoms of the disease or illness state. Holistic care also meant being mindful of the patient's family and including the patient's family and including the patient's family in the plan and delivery of care.

\subsubsection{Seeing the patient as having social and emotional needs}

Students frequently discussed the importance of the patient's social needs. Students realized the importance of the patient's family and other forms of social support. Humor was identified specifically as a straregy employed to help patients cope with their illness.

You're also like considering what's best for the patient, and looking at a patient as a whole and not kind of just going in and doing the medical. You're actually doing the medical part of it but you're also making sure you look at them as more holistic, like the family member is included, because it's the patient, the patient's family. (1st year nursing student)

On the bulletin board [in the drawing] there I have a get well card from the family and like a picture that somebody drew for the patient so that's like incorportating the family. (4th year nursing student) (see Figure 2)

Having like social support available to them if they need it. You know discharging a patient home if they need like extra supports in the home and making that available to them and educating them on where they can get special equipment or anything like that. (4th year nursing student)

I am in long-term care right now and we use a lot of humor there. I did that in palliative care too. Sometimes in tough situations a lot of patients like to joke around, and have a laugh with the nurses and their families and kind of lighten the mood in darker situations. I think that incorporating like bit of fun and humor into your practice is really important.
I personally wouldn't want a nurse who is really serious all the time, so I think it's nice to be able to relate to your patients in that way and feel around and see how they feel about it but if they want some fun, to give it to them. (4th year nursing student)

\subsubsection{Seeing the patient as person}

Despite heavy and stressful workloads students felt that it was important to remember the patient as a person and not just as an illness or disease that required treatment. Attending to the 'basics', treating the 'person', and just talking were all identified as ways of caring for the person.

On the bedside table I have a comb and a razor [referring to painting J and that to me are like the basics, like hygiene care for patients. Acute care especially, again where it is so busy and sometimes you get a bit overwhelmed with like medications or the skills that you have to do and having like a patient load but it's really nice to take the time to wash somebody's hair if they haven't had their hair washed in a week. I think that's extremely important, first just for general hygiene, but also just to make the patient feel better. It makes a huge difference like if you wash somebody's hair in the morning. It just changes the entire tone for the rest of the day. (4th year nursing student) (see Figure 2)

So at the top [of the painting] I just have a couple of quotes there. So the first one is, 'you treat a disease. You win, you lose. You treat a person and I guarantee you win, no matter the outcome' and that was by Patch Adams. I really like that quote because I think no matter where you go in nursing you're always trying to treat the person. I actually spent a day in palliative care and for people with end of life care or who aren't receiving treatment, it doesn't mean that we're withdrawing care. We're just withdrawing treatment. So that's why I like that quote. (4th year nursing student) (see Figure 2)

\subsection{Caring cannot be taught}

All students voiced that caring was something that could not be directly taught in nursing school. Rather, they felt that caring was something that needed to be embraced by nursing students and then put into practice. How care was actualized could be generalized, but was unique to each student. Sudents also shared that they believed caring could better be understood through self-reflection. Self-reflection within the curriculum was an effective strategy, they thought, to advance caring attitudes and behaviours.

\subsubsection{Caring can be embraced}

Four of the students stated outright that caring was something that could not be taught in nursing school. It was believed, however, that caring needed to be and could be embraced by 
reflecting on what kind of nurse you wanted to be.

I just think that the art of caring I guess, like the intuition aspect of it - I don't think you can kind of formally teach students that. I just think that's just the nature of these emotions and these feelings. (4th year nursing student)

Ifeel like it comes down to personal circumstances. It's different from person to person. So you can teach someone that this is how you would care for somebody but it's up to that person to take the initiative and kind of come up with their own ways. My main point is that I don't think its something that you can teach. (4th year nursing student)

I think that you can do as much as you can to prepare students about caring in nursing but ultimately I think they have had their own experiences and they have to kind of think back on their own practice. Now, especially in my fourth year, I'm thinking like, okay, I'm going to be a nurse. I'm going to be registered in less that 7 months. I have to start thinking about how I want to carry out my practice and how I want to hold my license. So I think it's the earnestness among the students to kind of take that upon themselves. The teachers can lecture about it all they want but ultimately if the student is not receptive to learning then obviously they are not going to take away anything. So I think the amount of knowledge that we're getting in nursing school is okay, like it is sufficient but there's only so much that you can teach. (4th year nursing student)

\subsubsection{Caring can be facilitated}

Despite the belief that caring was something that could not formally be taught, students stated that there were teachable skills and activities in the program that were important for helping with their understanding of the meaning of caring, and for developing good caring practice. These activities provided the opportuntiy for students to reflect upon behaviors in practice. Certain courses such as developing therapeutic relationships and mental health clinical were also identified by students as very important for helping them understand how to develop a good caring relationship with their patients. They stated that having reinforcement from faculty every year further facilitated what was learned in the courses. Students discussed the importance of the activity of self-reflection and a paper on the concept of caring.

Ifeel that after every clinical you have the self-reflecting kind of activity. They tell us to just reflect on your day; what did you feel that you did right? What did you do wrong? Is there anything you can improve upon? By reflecting you can kind of take a step back and analyze the situation and improve as a nurse, as a person. (4th year nursing student)

I remember in 'Introduction to Nursing' we did a paper where the topic was, 'what is the meaning of caring?' So even that helped because that was a whole paper on what it means to be caring. So that was helpful. (4th year nursing student)

I think that every year they [professors] bring up the idea of a therapeutic relationship. So no matter what we do the idea of a therapeutic relationship kind of gets reinforced and even the idea of caring goes right along with it. (4th year nursing student)

Having professors who were good role models and who validated student performance were also deemed highly valuable for reinforcing caring behaviors.

... but also, my therapeutics instructor, she is an amazing person and she taught us a lot about how to do patient interaction and she just had a caring way, like even when she talked to you as a student and like talked to you about your grades and about everything, she would actually act like she really cared, like during labs and stuff. I felt the same way with my clinical instructor. When she walked into the room she would say hi to us and she would talk to the patients and the patients all love her because she takes the extra time and listens to their stories and asks them how their day is going. (1st year nursing student)

When you do something or tell your professor about stuff and then they kind of validate you as a student. Yeah, you did this thing today and I felt you did really good with that and I guess just kind of getting that reassurance from your professors and things like that is really what helped me develop my caring essence and being able to engage the patients in the nurse-patient relationship. (4th year nursing student)

\section{Discussion}

In this study seven nursing students were asked to individually draw a painting that represented what caring in nursing meant to them followed by an interview to gain an understanding of how the meaning of caring was reflected in their painting. From the analysis of interview data we were able to more fully understand the meaning of caring for these nursing students. This study provided a venue for students to both create and respond to art. Responding to interview questions by reflecting on the paintings helped the students articulate what they believed to be the meaning of caring. Caring is an abstract concept, one whose description is complex and requires preciseness, theoretical clarity, and parsimony. ${ }^{[28]}$ The activity assisted them to critically self-reflect upon the meaning of caring and the kind of nurse they wanted to be and provided some clarity as to the key manifestation of a caring nurse. 
Caring was discussed by the nursing students as something internal to onself. Merleau-Ponty ${ }^{[29]}$ distinguished between the "body object" and the "body subject." As Merleau-Ponty describes, the lived body "body subject" is extending towards the world and creates conditions for interpersonal dimensions. The extension of the lived body allows for a connectedness with others possible. The situation of the patient is responded to by the nurse through sitting with the person, listening, talking, being empathic, warmth, and touch. The worlds of the nurse and patient are brought together and the patient feels cared for as a whole, as a human being with value and importance. Oftentimes this connection is a brief caring moment that is not bound by time. Although the complexity of the caring relationship in nursing is not surprising, our findings support the need for more qualitative studies of caring and the nurse-patient caring relationship. As technology and treatment has grown there appears to be a gap between what patients want and need and what nurses provide.

The students in this study discussed caring as providing holistic care such as attending to the patients' social and emotional needs. This entailed including family members in the circle of care, providing good discharge planning, providing nursing education and using humor. Interestingly none of the seven students emphasized caring as the provision of medical care to patients. Although they acknowledged the importance of competent care, it was discussed in terms providing appropriate cultural care, keeping abreast of policy and best practice guidelines, and the incorporation of research into practice. Providing competent care often meant advocating for patients. Advocacy is an important concept in nursing and our code of ethics stipulates that nurses act as advocates for patients. The process of becoming prepared as a competent nurse includes being an effective advocate for patients, and having the ability to address conflict and manage ethical delimmas. However, nursing students are often challenged when preparing for this role. They are in a position where they require supervision by a nurse with more authority and the consequences of speaking up when poor practices are identified can lead to a range of ramifications such as being ostracised, bullied, or experiencing other forms of horiontal violence $^{[30]}$ and fear regarding how it may impact their ability to successfully complete their clinical placement. ${ }^{[31]}$ This is supported by two of the students in our study who equated advocacy with being brave. These students felt that advocacy was an important component of caring yet it required bravery to stand up against what they saw as the 'powers-that-be'. Nursing students are most likely to speak up when they are concerned for the patient and when they perceive the environment to be supportive. ${ }^{[32]}$ The relationship between nursing students and their supervising nurse is a crucial factor when

Published by Sciedu Press deciding to advocate for best practice. ${ }^{[33]}$ It is not enough to include advocacy in nursing curricula. As faculty we also need to be supportive of students in the clinical area, who, when caring for their patients feel the need to speak up and do what they feel is best to uphold the patient's rights.

In a quantitative study to investigate the significant differences of first and third year nursing students in the mean scores for the Caring Behaviours Inventory, ${ }^{[34]}$ it was found that the most important caring behaviours included having good relationships with patients, being respectful of patients, being sensitive to them, helping them, teaching them and being appreciative of them. Having good nursing skills and knowledge were also deemed as important. The Caring Behaviours Inventory is the most frequently used empirical tool to measure caring in nursing research, with well established reliability and validity. ${ }^{[35]}$ However, our study findings indicate that although several of the caring behaviours deemed important for our sample of nursing students were congruent with those identified ${ }^{[34]}$ on the Caring Behaviours Inventory, caring behavors and the nurse-patient caring relationship was much more complex. Our findings show that caring was viewed by the students as something that came from within the person, a being present, exuding warmth and the ability to put oneself in the other's situation. In 1974, Vandevelde, in a letter to the American Journal of Nursing, wrote, "True nursing comes from within-from a desire to help people in need." ${ }^{[36]}$ As nurses we hope this is true of all nurses, and as disussed by Vandevelde forty-five years ago, we are still discouraged when we sometimes see the contrary. The students' perspectives within our study are encouraging and there is much enthusiasm for caring among these future nurses.

Although the fourth year students had more stories and examples than first year students to discuss during the interview, there was consistencey between groups in meaning of caring behaviors and the nurse-patient caring relationship. There were several nursing behaviours perceived as caring practice by the nursing students in this study. Amongst those identified was doing physical tasks such as providing 'basic' care. As a practice-based discipline, clinical learning is an integral element of any nursing program, thus the focus on physical and technical aspects of care by nursing students within nursing programs is common. ${ }^{[37]}$ However, students saw the provision of what might be seemingly mundaine tasks such as basic care as more than just the provision of care. For example, cleaning the patient's nails was also an act of empathy, the ability to put oneself in the place of another. Fast paced technological environments often challenge nursing students to demonstrate such caring interactions with patient and opportunities such as these are often overlooked. It is known that care encounters are part of a deeper relational 
process and an understanding of the patient as person. ${ }^{[38]}$

The literature has shown that faculty members' caring behaviours influence nursing students' caring behaviours in a positive manner. Through faculty members' role modeling, nursing students can be professionally educated to devlop the competence of caring. ${ }^{[39]}$ Furthermore, caring interactions between faculty members and nursing students is considered a transpersonal evolutionary process in nursing education. ${ }^{[40]}$ Because caring was viewed existentially, students in our study believed that caring was something not easily taught in nursing school. Despite this they believed that it was important for faculty to facilitate student opportunities to embrace caring through various activites so that that students could reflect on what kind of nurse they wanted to become. Certain courses such as Introduction to Nursing, Developing Therapeutic Relationships and mental health clinical practice courses were identified as very important for helping them understand how to develop good nurse-patient relationships. Reinforcement of caring principles across the curriculum was deemed imperative to fostering competence. Having faculty members who were good role models and who provided positive reinforcement when they exhibited good caring behavious were also seen as very important.

Caring as coming from within means that integrating caring science and caring competencies throughout the curriculum may not guarantee caring graduates. However, offering faculty development on the pedagogical development of caring competencies may prove beneficial. Furthermore, with an increase in simulated learning in nursing education it is important to make caring an integral component of each simulation. With the increase in highly paced and highly technological clinical practice areas it is important that nursing faculty remain committed to the professional, ethical, and social responsibility to inspire future nurses to practice from an innate ethos of caring.

\section{Limitations}

Although it is never the aim of phenomenology to generalize findings to the greater population, our study was limited by having participants from only one nursing school. Also, six of the seven students were female. The data gathered from other students within this nursing school may have added breadth and illumination. Furthermore, the meaning of caring and the caring nurse-patient relationship reflects the curriculum of this particular nursing school as well as specific teacher-student relationships. Other curricula from different schools of nursing utilizing different clinical set- tings may provide a different perspective. But it is promising that the meaning of caring for the nursing students in our study went beyond the technological aspects of nursing care to a more existential view of caring and the nurse-patient caring relationship. Another limitation is that it is possible that those who agreed to participate felt comfortable with the idea of painting and therefore had a positive view of using art to help articulate their views of caring. Students who are uncomfortable with painting might have had a completely different perception of art-based inquiry had they participated.

\section{Conclusion}

This study aimed to explore the meaning of caring and the nurse-patient caring relationship using arts-based inquiry for seven nursing students in one baccalaureate nursing program. Interpretation of the interview data revealed that nursing students value caring as a core concept in nursing. The meaning of caring was viewed as coming from within themselves, as a presence with the other within a therapeuric relationship. Caring was also viewed by the nursing students as being the best nurse they could be; seeing the patient as person and being competent and brave. Caring behaviors within the nurse-patient caring relationship were also viewed as highly meaningful. Caring was about providing holistic care to the patient and family. Despite its importance, caring was viewed by the students as something that could not be taught in nursing school; however it could be role modeled and facilitated. However, while this study indicates that using arts-based inquiry can enhance nursing students' understanding of the personal meaning they attribute to caring further research is needed. Nursing education has a vital role to play in preparing students to work with vulnerable and marginalized population. Nursing students need to be not only highly skilled but also caring professionals who are able to meet patients' psychosocial and emotional needs. Nursing curricula must be focused on awareness of caring behavior for both nursing students and faculty members and on the development of a caring curriculum to provide the highest standards of patient care.

\section{ACKNOWLEDGEMENTS}

The authors would like to thank the students who took the time away from their busy schedules to participate in this study.

\section{CONFLICTS OF INTEREST DisClosure}

The authors declare that there is no conflict of interest. 


\section{REFERENCES}

[1] CNA: Code of ethics for registered nurses [Internet]. Ottawa: Canadian Nurses Association; c2017 [cited 2018 February 19]. Available from: https://www.cna-aiic.ca/html/en/Code-of-E thics-2017-Edition/index.html

[2] CASN: National nursing education framework. Final report. [Internet]. Canadian Association of Schools of Nursing; c2015. [cited 2019 February 19]. Available from: https://www. casn.ca/wp-content/uploads/2014/12 /Framwork-FINAL-SB-Nov-30-20151.pdf

[3] Andersson EK, Willman A, Sjöström-Strand A, et al. Registered nurses' descriptions of caring: A phenomenolographic interview study. BMC Nurs. 2015; 14(16): 1-10. PMid:25834478 https//d oi.org/10.1186/s12912-015-0067-9

[4] Roach MS. The human act of caring: A blueprint for the health professions. Ontario: Canadian Hospital Association; 1987.

[5] Leininger M. Transcultural care diversity and universality. A theory of nursing. Nursing and Health Care. 1985; 6(4): 209-212.

[6] Watson J. The theory of human caring: Retrospective and prospective. Nursing Science Quarterly. 1997; 10(1): 49-52. PMid:9277178 https://doi.org/10.1177/089431849701000114

[7] Watson J. Watson's theory of human caring and subjective living experiences: Carative factors/carative processes as a disciplinary guide to the professional nursing practice. Texto Contexto Enferm, Florianopolis. 2007; 16(10): 129-135. https://doi.org/10.159 0/S0104-07072007000100016

[8] Webb C. Caring, curing, coping: Towards an integrated model. JAN. 1996; 23: 960-968. https ://doi.org/10.1046/j.1365-2648. 1996.09715.x

[9] Porr C, Egan R. How does the nurse educator measure caring? International J Nurs Educ Schol. 2013; 10(1): 1-9. PMid: 23629467 https//doi.org/10.1515/ijnes-2012-0011

[10] Goh ML, Vehvilainen-Julkunen K. Hospitalized patients' satisfaction with their nursing care: An integrative review. Singapore Nurs J. 2016; 43(2): 11-27.

[11] Doane GH, Varcoe C. How to nurse: Relational inquiry with individuals and families in changing health and health care contexts. Baltimore: Lippincott Williams \& Wilkins; 2015.

[12] McClelland LE, Gabriel AS, DePuccio MJ. Compassion practices, nurse well-being, and ambulatory patient experience ratings. Med Care. 2018; 56(1): 4-10. PMid:29112049 https ://doi .org/10.1 $097 /$ MLR . 0000000000000834

[13] Curtis K. Compassion is an essential component of good nursing care and can be conveyed through the smallest actions. Evidence-Based Nurs. 2015; 18(3): 95. PMid:25673277 https ://doi.org/10.1 $136 /$ eb-2014-102025

[14] Almost J, Wolff AC, Stewart-Pyne A, et al. Managing and mitigating conflict in healthcare teams: An integrative review. JAN. 2015; 72(7): 1490-1505. PMid:26822008 https ://doi .org/10.1111/ jan. 12903

[15] Grobbel CC, Rowe L. Exploring pre-nursing students' perceptions of caring and nursing: A phenomenological study. IJHC Journal. 2014; 18(1): 8-16. https://doi.org/10.20467/1091-5710.18.1.8

[16] Landers MG, Weathers E, McCarthy G, et al. Professional caring: Descriptions from student nurses' perspectives through their educational program. Int J Human Caring. 2014; 18(4): 52-58. https://doi.org/10.20467/1091-5710.18.4.52

[17] Chen AMH, Kiersma ME, Yehle KS, et al. Impact of the geriatric medication game $(\mathbb{R}$ on nursing students' empathy and attitudes toward older adults. Nurs Educ Today. 2015; 35(1): 38-43. PMid: 24912741 https://doi.org/10.1016/j.nedt.2014.05.005

Published by Sciedu Press
[18] Leonard CR, Zomorodi M, Foster BB. The impact of caring: Teaching students empathy through the patient voice. Creative Nursing. 2018; 24(1): 62-66. PMid:29490837 https ://doi .org/10.189 $1 / 1078-4535.24 .1 .62$

[19] Low M, Scala S. Medical memoir: A tool to teach empathy to nursing students. Nurs Educ Today. 2015; 35(1): 1-3. PMid:25459169 https://doi.org/10.1016/j.nedt.2014.10.001

[20] van Manen M. Reseraching lived expeience: Human science for an actin sensitive pedagogy. London, Ontario: Althouse Press; 1990.

[21] Gadamer HG. Truth and method. London: Sheed \& Ward; 1994

[22] Ricoeur P. The model of the text. In F. Dallmayr \& T. McCarthy (Eds.), Understanding and social inquiry (pp. 316-334). Notre Dame, IN: University of Notre Dame Press; 1977.

[23] Diekelmann N, Allen D, Tanner C. The NLN criteria for appraisal of baccalaureate programs. A critical hermeneutic analysis. National League of Nursing (Pub. No. 15-2253). 1989; 3-34.

[24] Diekelmann N, Magnussen-Ironside P. Hermeneutics. In Fitzpatrick, J. Enclycopedia of Nursing Research (pp. 243-244). New York: Springer Publications; 1998.

[25] Thomas SP, Pollio, HR. Listening to patients: A phenomenological approach to nursing research and practice. New York: Springer Publishing; 2002.

[26] Corbin J. Strauss A. Basics of qualitative research. Techiques and procedures for developing Grounded Theory. 4th ed. Thousand Oakes, CA: Sage Publications; 2008.

[27] Lincolyn YS, Guba EG. But is it rigorous? Trustworthiness and authenticity in naturalistic inquiry evaluation. New Dir Program Eval. 1986; 1986: 73-84. https://doi.org/10.1002/ev. 1427

[28] Morse JM, Bottoroff JL, Neander W, et al. Comparative Analysis of Conceptualisation and Theories of Caring. London: Sage Publications; 1992

[29] Merleau-Ponty M. Phenomenology of Perception. (2011/1945). London: Routledge. (D. Landes, Trans.).

[30] Bickhoff L, Levett-Jones T, Sinclair PM. Rocking the boat - nursing students' stories of moral courage: A qualitative descriptive study. Nurs Educ Today. 2016; 42: 35-40. PMid:27237350 https : //doi.org/10.1016/j.nedt.2016.03.030

[31] Iron R, Smith K, Nimmo S, et al. Factors influencing student nurse decisions to report poor practice witnessed while on placement. Nurs Educ Today. 2015; 35: 900-905. PMid: 25765226 PMid:25765226 https://doi.org/10.1016/j.nedt.2015.02.006

[32] Barnsteiner J, Disch J. A just culture for nurses and nursing students. Nurs Clin North Am. 2012; 47(3): 407-416. PMid:22920431 https://doi.org/10.1016/j.cnur.2012.05.005

[33] Levett-Jones T, Lathlean J. 'Don't rock the boat': nursing students' experiences of conformity and compliance. Nurs Educ Today. 2009; 29(3): 342-349. PMid: 19056151 https ://doi.org/10.1016/j . nedt. 2008.10 .009

[34] Mlinar S. First- and third-year student nurses' perceptions of caring behaviours. Nurs Ethics. 2010; 17(4): 491-500. PMid:20610582 https://doi.org/10.1177/0969733010364903

[35] Watson J. Assessing and measuring caring in nursing and health sciences. New York: Springer Publishing; 2002.

[36] Vandevelde M. True nursing comes from within. AJN. 1974; 74(8): 1408. https://doi.org/10.1097/00000446-197408000-000 05

[37] Jack K. "Putting the words 'I am sad', just doesn't quite cut it sometimes": The use of art to promote emotional awareness in nursing students. Nurs Educ Today. 2012; 32: 811-816. PMid: 22579882 https://doi.org/10.1016/j.nedt.2012.04.020 
[38] Benner P. From novice to expert, excellence and power in clinical nursing practice. Menlo Park, CA: Addison-Wesley Publishing Company; 1984.

[39] Labrague LJ, McEnroe-Petitte DM, Papathanasion IV, et al. Impact of instructors' caring on students' perceptions of their own caring behaviors. J Nurs Scholar. 2015; 47(4): 338-346. PMid: 25959595 https://doi.org/10.1111/jnu.12139

[40] Wade GH, Kasper N. Nursing students' preceptions of onstructor caring: an instrument based on Watson's theory of transpersonal caring. J Nurs Educ. 2006; 45(5): 162-168. PMid: 16722498 